\title{
THE EMOTIONAL EXPERIENCE OF STUDENTS DURING COVID-19 PANDEMI ON ENGLISH E-LEARNING IN JUNIOR HIGH SCHOOL
}

\author{
${ }^{1}$ Ines Putri Pratiwi ${ }^{2}$ Mansyur Sri Sudarso ${ }^{3}$ Maya Rahmawati \\ University of Singaperbangsa Karawang \\ email: inesptr0311@gmail.com
}

\begin{abstract}
The Covid-19 pandemic that has spread throughout the world has caused schools, universities to temporarily close and requires them to carry out teaching and learning activities at home with online or e-learning. This study focuses on exploring what emotions that students felt, the obstacles of e-learning that affect their emotions, and strategies that they used to overcome the obstacle. The research design that this study used is a narrative inquiry by collecting data through semi-structured interviews. The results of this research shown students felt both positive and negative emotions. They felt joy and excitement at the beginning but later they felt negative emotions such as anxiety, fear, stressed for learning alone without a teacher, and fell isolated. Those negative emotions provide some problems for students' learning include internet connection problems, demands for time management, and difficulty to communicate with teachers. Therefore, students also have strategies such as learning for better understanding, finding some fun activities to relieve stress when learning at home. Then, with all the problems and emotions that students felt, they prefer face-to-face learning to E-learning.
\end{abstract}

Keywords: Emotional experience, E-learning, Face-to-face learning

\section{INTRODUCTION}

In the field of education, face-to-face learning in classrooms is preferred by the majority of students. Bali and Liu (2018) stated from their research that most students choose face-to-face learning in terms of social presence, social interaction, and satisfaction. However, since Covid19 is widespread in certain countries, particularly Indonesia, all activities should be conducted out from home these days. Nadiem Makarim, Indonesia's Minister of Education and Culture, issued a Circular Note instructing schools and educational institutions to do learning activities at home and stop regular teaching and learning in the meantime. In line with the statement, Elearning is appropriate for teaching and learning activities during Covid-19. Gherhes et al (2021) stated that E-learning is more intended to be student-centered, different with face to face learning which is more teacher-centered. Suartama (2014:20) also states that E-learning is learning activities, and tasks that can be accessed anywhere and anytime. Teachers may use multimedia to enhance the learning material, which is available from a variety of sources.

However, the majority of Indonesian students are inexperienced with e-learning. They still have some problems with this learning method. One of the problems is their emotions in E-learning. According to Oluwalola (2015), Emotions are an enormous effect on e-learning and conventional learning. Therefore, in that case, students' emotional also relate and affect students learning results when studying with E-learning in this pandemic

Cleveland-Innes and Campbell (2012) stated that Zembylas in his research analyzed the emotional presence of learners. His study's findings are divided into two themes: positive and negative emotions related to E-learning. The positive emotions are excitement, joy, and enthusiasm for the flexibility of online learning. Meanwhile, negative emotions included anxiety and fear for the mode of online learning. Moreover, their negative emotion can be the demand for time management, technology, structure, feeling isolated, socializing, and struggling to communicate better with their teacher and classmates. Therefore, the major issue is that students are under pressure to take on numerous responsibilities. The students struggle to maintain a balance between their family, professional, and social lives, making it challenging to fulfill various command programs. 
Furthermore, this study explores the students' emotional experience in learning English with Elearning during Covid-19. The researcher is interested in the students' emotional responses to English learning through E-learning amid Covid-19. Based on the explanation above, the researcher is eagers to explore students' emotional experience in English with E-learning. Moreover, this study about students' emotional experience is relatively uncommon in Indonesia. Thus, the researcher was curious and conducted this study.

\section{Research Methodology}

This study used a narrative inquiry as a design in a Qualitative approach that gain the story of individual emotional experience on English E-learning during Covid-19 by analyzing. The use of narrative also makes sense of the story of how people's lives change and know who they are( Bruner, 1990). This participant of this research included three participants. For data collection are used semi-structured interview. The interview is conducted by WhatsApp Voice Call and Voice Note. Data Analysis is from Braun and Clarke (2006) included, Familiarizing with the data (Interview Transcript), Generate the initial codes, Theme's searching, Review the theme, Define and naming the themes, and Produce the report/manuscript.

\section{FINDINGS AND DISCUSSION}

This chapter shows the research finding and discussions that have been found through the interview. The data collected from the interview are transcribed and analyzed. The finding and discussion are the answer to this research question. This chapter will be presenting the interview of respondents that have three heading themes about their emotional experience with English Elearning.

\section{Students' emotions about the implementation of e-learning}

The first theme of the finding and discussion obtained that the participants' feelings or emotions during E-learning. It shows that S1 begins to enjoy E-learning. She said she didn't need to get up early in the morning. Another reason is that she is free to access Google for educational purposes. She showed that with E-learning for the first time she feels more excited even though it is just temporary because that has been too long so, in the end, she said wants to go to school.

"At first, I enjoyed e-learning, it was fine at first. Don't get up early, don't feel the cold when I take a shower, there's Google too. But lately, I do not enjoy like the first time because it's been too long at home, and I want to go to school". (S1, WhatsApp Voice Call Interview)

Meanwhile, the two other participants said that E-learning for the first time is kind of shocking for her because of the sudden situation's change. Moreover, for time being, she has gotten used to E-learning and felt happy that stay at home even though she difficult to understand the material, but she quietly enjoyed it. It becomes habitual for them and quietly relish learning from home. They didn't need to get up early, wear the uniform, and were afraid that will come late to school. With E-learning, she becomes more relaxed and comfortable doing the assignments while listening to music and eating snacks.

"In my opinion, when it started, I was surprised but gradually I feel happy, and I've gotten used to it. When I've been studying online for a long time, Ifeel nice. Because yes, I can stay at home and study, I don't have to wear uniforms, I don't have to be in a hurry that I'm late, I can study while listening to music and have a snack, it's really good. It's fun" (S2, WhatsApp Voice Call Interview)

"In my opinion, how about it when I was early, it was fun because I had to go straight to school without meeting my friends and teachers. But in the end, I'm happy, even though it's good to study at home, but I feel more stressed. In the beginning, I was surprised maybe because of learning online, so the atmosphere is also different from when I am in class. But now that I'm used to it, I'm more relaxed and I just want to stay home hehe" (S3, WhatsApp Voice Note Interview)

However, all of them felt the emotion that carried out the pleasant feeling when studying with 
E-learning, but they also felt difficult to study without teachers. For example, when students want to ask some difficult material to the teacher, but some teachers didn't even answer their message or answer the message late. Those makes S1 afraid and worried about their assignment also the teacher's opinion about her when asking some questions. So, she tried to understand by herself and ask her friend to resolve that difficult material or assignment.

"There are some materials, or I don't know the meaning of some questions. I want to ask the teacher but I'm afraid the teacher will reply late and sometimes I'm afraid that the teacher thinks I don't understand the lesson that I just learned yesterday. Well, I usually look at the book first and then ask the teacher. Some teachers don't reply, so I have to understand myself or ask a friend" (S1, WhatsApp Voice Call Interview).

Similarly, S2 is confused and afraid that she will collect the difficult assignment late because of the deadline. S3 is also worried about the lesson because there is some teacher who hardly teaches her and just gives tasks without explaining the material.

"I've been worried like that. It happened when I'm working on assignments and I don't understand but it's already on the deadline, so I'm afraid I'll be late. Then I want to ask the teacher, but the teacher didn't read it. I'm confused and worried too when in a situation like that". (S2, WhatsApp Voice Call Interview).

"Sometimes the teacher is rarely available, so there is no task. It makes me worry, how is the lesson going. There is the teacher who gives assignments and didn't explain the material and makes it difficult.”. (S3, WhatsApp Voice Note Interview).

Therefore, Their English teacher happened to give them a task to upload a video on WhatsApp status. The teacher gives them a task to describe someone and try to speak in the video. All participants' opinions about this kind of task are similar. They didn't like those videos of them speaking are uploaded to social media. The participants states that they feel ashamed, not confident, and scared because all of their contact in WhatsApp is look at their videos. Even though they didn't like it, they still upload feel responsible for it.

"At that time, I made a story in English, while learning to speak, the teacher asked me to make a video and upload it to WhatsApp status. But on WhatsApp status, I'm a little scared, because if the people I've contacted watch the videos, I don't know if I'm speaking right or not, so I'm a bit embarrassed too". (S1, WhatsApp Voice Call Interview)

"Yes, I did but I didn't like it. It's like making a description of someone's profile in English and then the video is uploaded when I uploaded the video on WhatsApp status. I don't like when someone sees it. I feel ashamed and I'm not confident, but I still upload for my scores". (S2, WhatsApp Voice Call Interview)

Moreover, all of those happen when the pandemic situation, they felt isolated because they always at home while studying the material and assignments that they don't understand without a teacher. S3 states there is one time that she was sick, and she doesn't want to do tasks. She didn't even leave her home all day and do all assignments that she ended up doing the task he put off earlier due to illness.

"There was a time when I was sick and wasn't in the mood to do the same tasks. Well, I was there doing my job, really speeding until I didn't leave the house and didn't leave the house all day." (S3, WhatsApp Voice Note Interview)

Besides, the implementation of E-learning that makes participants feel isolated, also makes them stressed. For example, two of the participants feel stressed because they had more tasks than usual. S1 addresses that she feels stressed because the teacher did not directly convey the material and she use to talk with friends in school. It also makes her angry more often because of the pressure that she experiences. Similarly, S2 states that she got a hard time answering an assignment and it makes her stressed to think about it.

"Yes, while I was learning online, I felt stressed because I had more work than usual, there's no explanation from the teacher and I usually talk with my friends, even though it's nice to be at home, but it's also not. I was so stressed that I got angry more often 
because I felt pressured to study at home”. (S1, WhatsApp Voice Call Interview)

"Yes, I have been like that, because at that time I was working on a very difficult task, and I was stressed thinking about the answer because I didn't know what to answer".

(S3, WhatsApp Voice Note Interview)

The material and assignment are related to their score if those are difficult and make them worried. The two other participants affected the emotional psychology when they were about to take their report cards. They think their scores will be different and go down because they didn't understand the materials and makes people around them disappointed.

"I felt it. I was afraid when I was waiting for the report card. I'm afraid my score will go down". (S1, WhatsApp Voice Call Interview)

"I didn't like it when I'm afraid that my score going down. I'm also afraid while waiting for the score of the report card, I'm already afraid, I feel that the score will go down and make everyone disappointed in me". (S2, WhatsApp Voice Call Interview).

Thus, all participants feel negative or positive feelings. They felt happy and excited because they can study at home without having to go to school, wear school uniforms, and can study at home more relaxed. In line with their positive feelings, they also feel these negative feelings. They are afraid that their scores will drop because of online learning which makes them not understand well the material presented. In addition, the online learning system that requires them to upload a task in the form of a video makes them worried when people see their videos. They also feel isolated because they have to stay at home and end up stressed because of the tasks. All these positive and negative feelings affect their learning performance, but their negative feelings are more dominant than positive feelings

2. E-learning obtained the obstacles for students' emotional experience during Covid-19 There are some obstacles that participants have experienced. The first is S1 starts to seem difficult to manage her time at home. She states that when study and helping her mother at the same time is hard for her. She is like the type who should focus on one work. For example, when she is working on her assignment and her mother call for help, and if she did help her mother, she forgot the material and answer. However, for a long time, she got used to it.

"In the beginning, it was really difficult, for example, when I was working on a task, then suddenly my mother calls me for help. Sometimes if I remember the answer, then I already understand the material but my mother call. Then when I come back to work on the question again, I forgot. It was like that at first, but lately, I've gotten used to it." (S1, WhatsApp Voice Call Interview)

The two other participants are different from S1. They didn't have a problem managing their time between study and some activities at home. Both of them didn't bother about it. Their parents understand them and don't ask for some help often, so they still manage their time.

"It's not that difficult because I'm not that busy, from morning until noon I will study. If I can be on time, at noon, all tasks are finished, I will continue praying and take a nap. But only in the afternoon if mom asks for help, I will help but if not, I watch TV." (S2, WhatsApp Voice Call Interview)

"It's not hard, sometimes if I'm doing an assignment, my mother understands that, so she rarely asks for help. She will ask but maybe when I'm done with tasks. So yeah, I can manage time to study and with other things at home”. (S3, WhatsApp Voice Note Interview)

The implementation of E-learning must be related to the use of an internet connection. This is one of the problems that affect teaching and learning activities for both teachers and students. If the internet connection is bad, it will cause problems, not being able to access assignments or materials and not being able to submit the assignment itself. The participants also experienced that problem, they have experienced the connection problems that made it difficult for them to study online. S1 states that the Wi-Fi in her home happened to be off because the cable Wi-Fi of her neighbors is broken. When that happen, she was watching a video of the material subject 
and suddenly the video is buffering. She panicked and just waited for the Wi-Fi to turn on, but the problem is it will make her forget about the answer and makes her lazy to watch the video again.

“Yes, at that time the neighbor's Wi-Fi cable broke, at that time I didn't know, and I was watching video material suddenly it took too long to load. Then I went out and asked my mother, it turned out that my Wi-Fi was off, I panicked at that time. That's because I haven't written anything yet. I'm just waiting for the Wi-Fi to turn on. But when I know the material and I didn't continue to work, it will make me forget and I'm too lazy to watch the video again”. (S1, WhatsApp Voice Call Interview)

The two other participants also state that sometimes there is no connection to their Wi-Fi or mobile data network. provide a mobile data network just in case their Wi-Fi goes down. However, when the Wi-Fi and cellular data network is bad, that's a problem and difficult for them to see the assignment.

"Yes, I'm at home using Wi-Fi, so I rarely have problems, only if the Wi-Fi continues to error and there's no quota, that's the problem, I'm stressed, I'm being rushed for work but there's no signal, so it's difficult". (S2, WhatsApp Voice Call Interview)

"Yes, if there was that time, the first time I didn't use Wi-Fi, I used mobile data network, but suddenly the data ran out, I couldn't see the assignment". (S3, WhatsApp Voice Note Interview)

Besides, another thing that becomes a problem when implementing e-learning is when they communicate with teachers and friends. According to S1, each teacher is different. Some teachers will respond quickly when they ask questions via chat and some answer late or don't even reply at all. This made things difficult, but S1 decided to ask her friend because the communication between her friends was not too difficult.

"Sometimes it's hard to ask the teacher but it depends on the teacher himself. Like I said before if the teacher is ready or online, usually, the answer is fast, but if it's off, I wait a very long time, I sometimes do something else first. If the teacher doesn't answer, I ask my friend". (S1, WhatsApp Voice Call Interview)

It is different with $\mathrm{S} 2$, when there is a difficult subject, she prefers to ask her friend often than her teacher. The difficulties to communicate with her friends are not as hard as when she asked the teacher. Similar to S2, S3 also barely asks something related to the teacher. She states that if there is some difficult material, she always tries to understand it by herself or asks her friends.

"Not really, because if there's a subject that I don't understand, I will ask my friends more often, maybe there are friends who understand better. If none of my friends understand, then I ask the teacher, it's not difficult to communicate with them." (S2, WhatsApp Voice Call Interview)

"I'm a person who rarely asks the teacher if something is difficult, I will ask my friend. I'm just embarrassed by the teacher, even though it's through chat. I'll try to understand it myself, or if I'm stuck, I'll ask my friends. The point is that I rarely ask or chat with the teacher". (S3, WhatsApp Voice Note Interview)

However, the problems experienced by the participants resulted in negative feelings in Elearning. The problem of internet connection (Wi-Fi) is one of the problems that all participants experience when learning E-learning. In addition, one participant experienced a difficult communication problem with the teacher when asking about confusing material. The other two participants preferred to understand the material themselves or ask friends rather than the teacher. One participant also found it difficult to manage time while studying and doing activities at home, but the other two were not as difficult as dividing the time because their parents understood their situation

\section{Students' strategies to resolve the obstacles during Covid-19}

The strategies of the participants are all different and depend on how they resolve the problem during Covid-19. S2 states that she talks more to her parents about her problem when online learning during Covid-19. She also tries to look for something fun, for example listening to 
music to relieve her stress.

"For me, I just talk more to my parents, especially to my mother, about my difficulties when I study online, and when I'm stressed, I try to find fun, like listening to music”. (S2, WhatsApp Voice Call Interview)

The two other participants have similar strategies. S1 stated that she learns more English through watching movies or songs in English. She did that to improve her English so, she is not hard to work on difficult material. S3 also stated she tries her best to bear all of the problems even though sometimes she complains.

"Yes, I'll just let it be. But I have to learn how to pronounce it in the future. I also like watching movies or songs in English". (S1, WhatsApp Voice Call Interview)

"I don't know, I'll just try my best. Although sometimes I complained, and I don't know what I should do. The problem is that there are good and difficulties in learning online, so I'll just do it" (S3, WhatsApp Voice Note Interview)

Therefore, they are all given the same opinion that face-to-face learning is better than Elearning. They always said that they want to go to school although the Covid-19 still exist. They want to learn with the teacher and together with their friends. S2 stated that she is more understands the material better than online and she can graduate with satisfactory scores by face-to-face learning.

"If I should choose, I'm also confused because E-learning is also good, but I prefer to study at school so that I can understand better. I want to have a better understanding of the material so I can graduate with good scores. If I could, I hope I could learn it at school and not online anymore. So, I prefer to study at school”. (S2, WhatsApp Voice Call Interview)

Other participants also chose to study at school. The teacher that delivers the subject material directly makes them understand better. In addition, they can directly ask the teacher if there is something they do not understand. Studying at school also makes them more excited than stressed alone at home.

"In my opinion, it is better to study at school, because I meet teachers directly in class. The material is delivered directly from the teacher and I can ask directly to the teacher. So, I am more enjoy studying at school”. (S1, WhatsApp Voice Call Interview)

"I'm confused to choose, but I enjoy studying at school because I understand the material better and I can meet friends and teachers. Yeah, I am also more excited at school, not stressed alone studying at home”. (S3, WhatsApp Voice Note Interview)

Thus, participants are used simple strategies that can make them more comfortable and easier to study through E-learning. She learns to gain better knowledge about that material and also looks for some fun activities to relieve the stresses when studying with E-learning during the pandemic

The researcher concluded that three participants felt both positive and negative emotions experienced in English E-learning. The outcomes are influenced by emotions that linked positive and negative outcomes to positive and negative emotions (Cleveland-Innes and Campbell, 2012). However, all the participants happened to feel joy, excited, relieved and felt at ease for studying at home in a pandemic situation. Fredrickson $(1998,2001)$ stated that the emotions such as happiness and joy are feeling that act for the positive emotion that take subjective pleasurable feeling with them. The outcome that is conducted by their positive emotions are they become more enjoy at home. Two of them begin to feel shocked because of the change from face-to-face learning to E-learning but as time goes by, they felt amusing being at home. In the end, all of them want to go to school instead of learning at home although it was enjoyable. On the other hand, the participants seem to enjoy E-learning at the beginning, but slowly it started to disturb them because learning without teachers is hard for them. Besides, three of them mostly experienced negative experiences such as feeling stress, fear, anxiety when studying with E-learning. According to Cleveland-Innes and Campbell (2012), When obtained 
negative emotion during online learning could influence learning experience. It happens with all the participants in this research, they all are afraid if their scores will go down. The material that is not delivered directly by the teacher and some teacher who rarely explains the material during E-learning is one of the reasons they are afraid that their scores will drop. The same with their negative emotions, their results also obtained negative outcomes. Moreover, E-learning gains the stresses for them. They feel isolated because should always learn at home without social interaction. Social presence, teaching presence and cognitive presence are three elements that connect for supporting online learning (Cleveland-Innes and Campbell, 2012). Thus, the teacher that didn't convey material directly, stresses because lack of social interaction and decreasing of scores are all related to each other and acquire their negative emotions.

The researcher found that E-learning gains some problems for three participants. The first is difficult to communicate with their teacher. Two participants had a hard time communicating with their teacher to ask about something important. Related to that finding, Alawamleh et. al (2020) stated that the convenience of online learning is direct communication between teachers and students as well as fellow students. It is mean that direct communication in the school more effective than indirect communication such as message. They also experience unsupported WiFi or signal when studying online at home. This really gives an effect during the teaching and learning process, they cannot access assignments, send assignments, and also play videos of subject material. This is related to the statement from Dhawan (2020) that if there is no internet connection, Wi-Fi connections, and unavailability of proper digital tools can cause many barriers that make students lose the opportunity to learn. Therefore, the one of participants begins to find it difficult to manage time for study and activities at home. This is also related to the statement from Cleveland-Innes and Campbell (2012) express that the students are trying to combine their roles as a child, students, and their social life. This makes it difficult for them to act simultaneously at home. Meanwhile, two participants did not find it difficult because their parents understood when it was time for them to study online.

On the other hand, three participants did their strategies to resolve their problem. One of the participants express her feeling to her parents and do some fun activities to relieve stress because of E-learning. The rest of them are trying to study harder and try their best to study in this Covid-19 situation. However, they also have the same opinion that they want to go to school. They prefer that teacher will directly convey the material for their better understanding. Some researchers also found that face-to-face learning is more effective than online learning. According to Bali and Liu (2018) the interaction when online learning is still insufficient than face-to-face learning. Lack of social presence, lack of social interaction, and student satisfaction can be the reason for it. Therefore, all participants had their problems. Students feel that lack of community, technical problems, and difficulties in understanding instructional goals are the major barriers to online learning (Dhawan, 2020).

\section{Conclusion}

In this chapter, the researcher concluded that when study with e-learning greatly affects the emotions of students. Learning that requires using E-learning also has its advantages and disadvantages, especially in terms of emotional. The emotional condition of students is affected, especially during the pandemic period which requires them to study at home with E-learning. The positive or negative emotions still give the effect of their outcomes during online learning, especially in this pandemic situation. In finding also can be concluded that they feel happy in the beginning because they are learning at home without having to go to school, do not have to wake up early in the morning, do not wear a uniform, and casually study at home. However, despite feeling happy, they are dominant to feel negative emotions. They are always anxious and scared about their score because learning without teachers is hard for them. Feeling isolated because they are always at home and feeling stressed because of the many assignments and materials that are difficult for them to understand by watching videos without a teacher. In addition, there are several problems when implementing E-learning that makes them feel stressed and seem miserable because the teachers do not teach the material directly. All 
participants found it difficult to understand the material that was not delivered directly by the teacher. This is a big problem that causes various kinds of negative emotions. Internet connection problems, difficulty communicating, and managing time at home are also some of the reasons they have difficulty in e-learning. Moreover, they seem to use strategies that make them slowly resolve their problem in E-learning such as learning more hard to understand the material better even without a teacher and looking for something fun activities to relieve stress over all the problems in E-learning. However, the researcher learns that E-learning can provide both positive and negative along with the problem in it. Those emotions and problems make them want to go to school to do face-to-face learning if the situation got better.

\section{REFERENCE}

Alawamleh, M., Al-Twait, L. M., \& Al-Saht, G. R. (2020). The effect of online learning on communication between instructors and students during Covid-19 pandemic. Asian Education and Development Studies, October. https://doi.org/10.1108/AEDS-06-20200131

Bali, S., \& Liu, M. C. (2018). Students' perceptions toward online learning and face-to-face learning courses. Journal of Physics: Conference Series, 1108(1). https://doi.org/10.1088/1742-6596/1108/1/012094

Cleveland-innes, M., \& Campbell, P. (2012). Emotional Presence, Online Learning. The International Review of Research in Open and Distributed Learning, 13(4), 269--292.

Creswell, J. W. (2014). Research Design Qualitative, Quantitative, and Mixed Methods Approaches (Fourth Edi). SAGE publications.

Dhawan, S. (2020). Online Learning: A Panacea in the Time of COVID-19 Crisis. In Journal of Educational Technology Systems (Vol. 49, Issue 1, pp. 5-22). SAGE Publications. https://doi.org/10.1177/0047239520934018

Fredrickson, B. L. (1998). Cultivated emotions: Parental socialization of positive emotions and

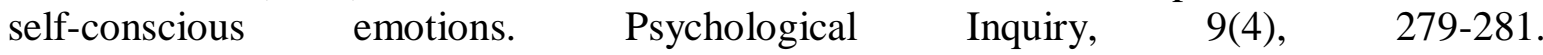
https://doi.org/10.1207/s15327965pli0904_4

Fredrickson, B. L. (2001). The role of positive emotions in positive psychology: The broadenand-build theory of positive emotions. American psychologist, 56(3), 218. https://psycnet.apa.org/doi/10.1037/0003-066X.56.3.218

Gherhes,V.; Stoian, C.E.; F arcas ,iu, M.A.; Stanici, M. E-Learning vs. Face-To-Face Learning: Analyzing Students' Preferences and Behaviors.Sustainability 2021, 13, 4381. https:// doi.org/10.3390/su13084381

Masyarakat, B. K. S. dan H. (2020). Sikapi COVID-19 Kemendikbud Terbitkan Dua Surat Edaran. Jakarta: Kementerian Pendidikan dan Kebudayaaan. Kementerian Pendidikan dan Kebudayaaan.

Oluwalola, F. K. (2015). Effect of Emotion on Distance e-Learning - The Fear of Technology. International Journal of Social Science and Humanity, 5(11), 966-970. https://doi.org/10.7763/ijssh.2015.v5.588

Suartama, I Kadek. (2014). E-Learning Konsep dan Aplikasinya. Singaraja: Universitas Pendidikan Ganesh. 